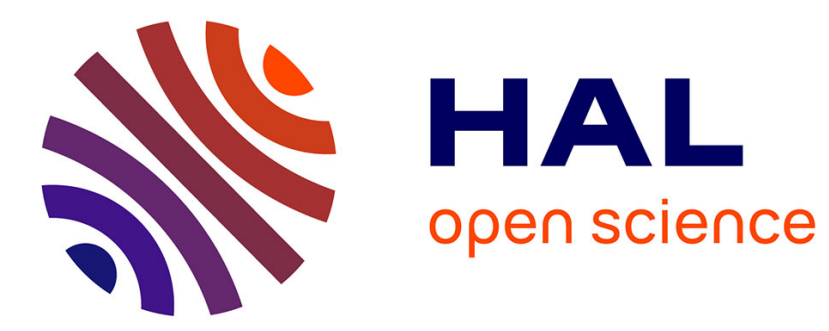

\title{
Origin of Invariant Gel Melting Temperatures in the c-T Phase Diagram of an Organogel
}

\author{
Elliot Christ, Christophe Blanc, Abdelaziz Al Ouahabi, David Maurin, \\ Rozenn Le Parc, Jean-Louis Bantignies, Jean-Michel Guenet, Dominique \\ Collin, Philippe J. Mesini
}

\section{To cite this version:}

Elliot Christ, Christophe Blanc, Abdelaziz Al Ouahabi, David Maurin, Rozenn Le Parc, et al.. Origin of Invariant Gel Melting Temperatures in the c-T Phase Diagram of an Organogel. Langmuir, 2016, 32 (19), pp.4975-4982. 10.1021/acs.langmuir.6b00995 . hal-01344912

\section{HAL Id: hal-01344912 \\ https://hal.science/hal-01344912}

Submitted on 14 Dec 2021

HAL is a multi-disciplinary open access archive for the deposit and dissemination of scientific research documents, whether they are published or not. The documents may come from teaching and research institutions in France or abroad, or from public or private research centers.
L'archive ouverte pluridisciplinaire $\mathbf{H A L}$, est destinée au dépôt et à la diffusion de documents scientifiques de niveau recherche, publiés ou non, émanant des établissements d'enseignement et de recherche français ou étrangers, des laboratoires publics ou privés. 


\title{
Origin of invariant gel melting temperatures in the $c-T$ phase diagram of an organogel.
}

\author{
Elliot Christ, ${ }^{\dagger}$ Christophe Blanc, ${ }^{\ddagger}$ Abdelaziz Al Ouahabi, ${ }^{\dagger}$ David Maurin, ${ }^{\dagger}$ Rozenn Le Parc, ${ }^{\star}$ Jean-Louis \\ Bantignies, ${ }^{\dagger}$ Jean-Michel Guenet, ${ }^{+\dagger}$ Dominique Collin, ${ }^{\dagger}$ Philippe J. Mésini ${ }^{\dagger *}$ \\ ${ }^{\dagger}$ Institut Charles Sadron, 23 rue du Loess - BP 84047, 67034 Strasbourg Cedex 2, France. \\ "Laboratoire Charles Coulomb, UMR 5221 CNRS-Université de Montpellier, 34095 Montpellier, France. \\ $\S$ International center for Frontier Research in Chemistry, 8, Allée Gaspard Monge, 67000 Strasbourg, France.
}

\begin{abstract}
Binary $c$ - $T$ phase diagrams of organogelators in solvent are frequently simplified to two domains, gel and sol, even when the melting temperatures display two distinct regimes, an increase with $T$ and a plateau. Herein, the $c$ - $T$ phase diagram of an organogelator in solvent is elucidated by rheology, DSC, optical microscopy and transmitted light intensity measurements. We evidence a miscibility gap between the organogelator and the solvent above a threshold concentration $c_{L}$. In this domain the melting or the formation of the gel becomes a monotectic transformation, which explains why the corresponding temperatures
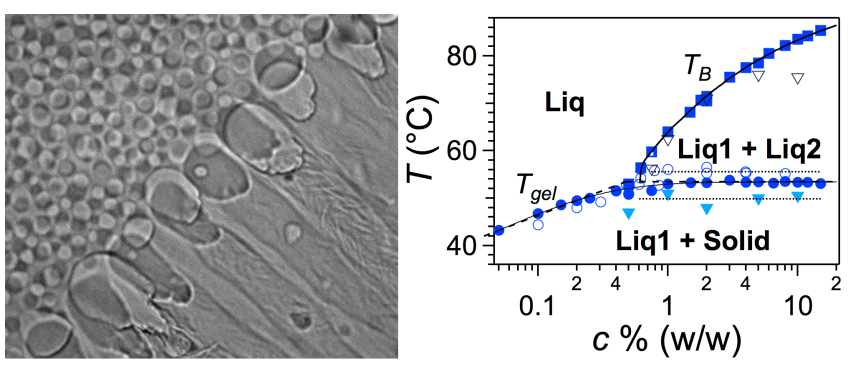
are non-variant above $c_{L}$. As shown by further studies by variable temperature FTIR and NMR, different types of H-bonds drive both the liquid-liquid phase separation and the gelation.
\end{abstract}

\section{INTRODUCTION}

The field of organogels has expanded during the last two decades and is now a recognized domain of soft matter science. $^{1,2}$ Their chemical diversity has been considerably developed with the aim of improving and tuning their properties for applications envisioned for example in tissue engineering and drug delivery, ${ }^{3,4}$ ion conducting materials ${ }^{5,6}$ or electronic devices $^{7,8}$. A large library of organogelators has been synthesized, but the mechanism of gelation and the molecular features necessary to design gelators are often poorly understood. This low predictability is partly due to the lack of thermodynamic studies and data available for correlation. As pointed lately by Weiss, ${ }^{9}$ the formation of gels itself is difficult to reproduce when experimental procedures are not described with enough details. For instance the cooling protocol is crucial: as shown by careful studies, ${ }^{10-12}$ the temperature of gelation, the morphology of a gel and its mechanical properties are function of the quenching temperature and of the cooling rate applied. More generally, the phase diagrams are seldom mapped out. Yet they are powerful tools to compare the efficiency of gelators and improve organogels properties. Their knowledge is also a prerequisite to study the mechanisms and the dynamics of the self-assemblies. Under different $c$ and $T$ conditions, the gel formation may follow different pathways that should be reflected in the phase diagrams. In the literature, most of phase diagrams of organogels are reduced to two domains labeled gel and sol, separated by a line often modeled by Schroeder-Van Laar's law. But sometimes, the gel melting temperatures follow two distinct regimes: $:^{13-16}$ a continuous increase and a plateau, markedly separated by a derivative discontinuity, which suggests the existence of two distinct domains. This complexity is revealed when a wide range of concentrations is explored. The lower concentration limit is imposed by the sensitivity of the measuring technique. Phase diagrams are mainly elaborated by rheology, since the gel is characterized by a solid-like rheological response. The sol-togel transition can be defined by the point where the real part $G^{\prime}$ of the shear modulus (storage modulus) becomes larger than the imaginary part $G^{\prime \prime}$ of the shear modulus (loss modulus) in the low frequency domain. Since the storage modulus decreases with concentration, it is hard to characterize gels at low concentrations. Alternatively, differential scanning calorimetry (DSC) can detect enthalpic changes associated to the self-assemblies, but is also subjected to a sensitivity threshold. For these reasons it is hard to distinguish the gel-sol boundary at low concentrations. Studies of organogels at higher concentrations are easier but are simply not considered in the literature since they are not relevant to characterize good gelators.

In previous work, we have studied a series of diamide forming gels in alkanes at low concentrations. The resulting gels are composed of self-assembled nanotubes. ${ }^{17,18}$ In the present study, in order to understand the different mechanisms associated to the gelation of such a compound, we have investigated its sol-to-gel transition by mechanical measurements, DSC, optical microscopy $(\mathrm{OM})$ and light intensity transmission. By a suitable choice of experimental set-up (stress rheometer with different types of cells, microcalorimeter) we achieved the 
study of the transition over two decades of concentrations (from $0.05 \%$ up to $15 \%$ ) and proved that the transition temperature increases with concentration below a given concentration and remains constant above. We have investigated this change of regime by optical microscopy and light intensity measurements to account for the observed plateau. In addition FTIR and NMR experiments provide insight into the different state of $\mathrm{H}$-bonding in the different phases.

\section{EXPERIMENTAL SECTION}

Materials. BHPB-10 was synthesized following a described procedure. ${ }^{17}$ Trans-decalin was purchased from TCI chemicals and purified by filtration on a column of silica.

Mechanical measurements. The real and imaginary parts of the complex shear modulus were measured with a commercial stress controlled rheometer (Haake, Mars III) working in the oscillatory mode. The principle of this device consists in applying a torque (i.e. a stress) and in measuring the strain transmitted though the sample. Depending on the gelator concentration, two types of measurements cells were chosen: plate-plate type (35 or $60 \mathrm{~mm}$ diameter) for high concentrations and Couette (DG41, Haake) for low concentrations. The temperature in the Couette cell was regulated by a heated bath (Haake F3) and that in the plate-plate cells by Peltier elements embedded in one of the plates. In both cases, the temperature was controlled between 25 and $95{ }^{\circ} \mathrm{C}$ at $\pm 0.05{ }^{\circ} \mathrm{C}$. The rheology experiments consisted in following, at a given frequency, the evolution of the complex shear modulus from the liquid phase to the organogel phase by progressively lowering the temperature from $95{ }^{\circ} \mathrm{C}$ to $25^{\circ} \mathrm{C}$ at a controlled cooling rate. For all experiments, shear measurements were performed with applied stresses lower than $5.10^{-2} \mathrm{~Pa}$ to ensure the data belong in the linear response regime. The thickness of the samples was $\sim 400 \mu \mathrm{m}$ for the Couette cell, and ranging between $400 \mu \mathrm{m}$ and $800 \mu \mathrm{m}$ for the plate-plate cells. Finally, measurements were preceded by an experiment conducted without the sample in order to know the residual stress, in phase with the strain, related to the experimental limit of the device. This residual stress has been subtracted from the rheological measurements presented in this study.

Optical microscopy. The solutions were observed and characterized with an optical microscope (Leitz 12 POLS) equipped with a $1024 \times 768$ pixel Sony CCD camera and a Nikon D50 digital camera. The studied mixture was first heated and homogenized into the isotropic phase in an oven. Rectangular capillaries (Vitrocom, $200 \mu \mathrm{m}$ thick x $2 \mathrm{~mm}$ wide) were filled with this solution by capillarity and immediately flame-sealed to prevent solvent evaporation. The capillaries were then placed in an Instec hot stage regulated at $\pm 0.1^{\circ} \mathrm{C}$ and observed in bright-field microscopy. The phase behaviors under cooling and heating were determined at a rate of $0.25{ }^{\circ} \mathrm{C} / \mathrm{min}$ like in FTIR experiments (see below).

Differential scanning calorimetry. The thermograms were recorded with a SETARAM III microcalorimeter. The measuring cell was filled with a BHPB10/trans-decalin mixture (between 100 and $200 \mathrm{mg}$ ). For amounts larger than $500 \mu \mathrm{g}$, BHPB10 was weighed directly in the measuring cell. Smaller amounts were introduced by a titrated solution of BHPB10 in chloroform and chloroform was evaporated under vacuum overnight before adding trans-decalin. The reference cell was filled with trans-decalin up to the same mass as the first cell to within $0.1 \mathrm{mg}$. The gel was formed during a first cycle of heating at $1{ }^{\circ} \mathrm{C} / \mathrm{min}$ and cooling at $0.3{ }^{\circ} \mathrm{C} / \mathrm{min}$. The thermograms were measured during a second cycle at $0.25^{\circ} \mathrm{C} / \mathrm{min}$.

Light intensity measurements. The liquid-liquid phase separation was also examined with an optical device able to follow the light intensity transmitted through the sample when temperature varies. A monochromatic light beam $(\lambda=632.8 \mathrm{~nm})$, provided by a HeNe laser (Melles Griot 05-LHP-151), successively passed through an attenuating filter $\left(10^{-3}\right)$, a pinhole $(50 \mu \mathrm{m})$, then through the sample over a 5 $\mathrm{mm}$ length and through a second pinhole $(150 \mu \mathrm{m})$. At the end, the beam was focused onto the objective of a CCD camera (Retiga 2000R) to measure its intensity. The light intensity measurements were carried out while temperature was decreased from $95{ }^{\circ} \mathrm{C}$ to 25
${ }^{\circ} \mathrm{C}$ at a constant and imposed rate. Typical exposure times were in the range of 500 to $2000 \mathrm{~ms}$. The sample temperature was controlled by an oven driven by a PID controller (SHINKO 100). In order to compare the results of light intensity measurements with those from mechanical experiments and those from microscopic observations the same cooling rate was applied to the sample.

FTIR. Mid-IR spectra $\left(600-4000 \mathrm{~cm}^{-1}\right)$ as a function of temperature between room temperature and $373 \mathrm{~K}$ were measured in solution on a Bruker IFS 66V spectrometer using a Mercury Cadmium Telluride detector, a $\mathrm{KBr}$ beam splitter and a blackbody source. For the micro infrared experiments, a Hyperion 2000 microscope (Bruker Inc.) coupled to the infrared spectrometer was used. The spectral resolution was $2 \mathrm{~cm}^{-1}$ and 128 scans were co-added for each spectrum. The liquid cell sample holders were filled with a weight fraction of 2 $\%$ of BHPB-10 in trans-decalin. The macroscopic gel formation was studied in a homemade liquid cell equipped with two $\mathrm{NaCl}$ windows spaced by an indium flat O-ring. The cell was inserted in a stage thermoregulated at $0.5{ }^{\circ} \mathrm{C}$. The liquid-liquid domain was studied by high temperature micro infrared with the same stage as for OM. The gel was placed between two $1 \mathrm{~mm}$ thick $\mathrm{CaF}_{2}$ windows. Micro IR spectra were performed inside and outside the droplets using a beam size of $80 \times 80 \mu \mathrm{m}^{2}$. The cooling or heating rate were the same as OM.

NMR. The NMR experiments were performed on a Bruker advance $400 \mathrm{Mhz}$. BHPB-10 (9.0 mg) and trans-decalin- $\mathrm{d}_{18}(441 \mathrm{mg}$, Cambridge Isotope Laboratories) and bis(trimethylsilyl)acetylene (TCI) were introduced in a NMR tube. The tube was sealed, heated and shaken until complete dissolution and allowed to cool at RT to form a gel. The weight fraction was 0.02 in the deuterated solvent The temperature probe was not calibrated, the temperatures indicated by NMR differ from other techniques from $\sim 5{ }^{\circ} \mathrm{C}$. The spectra were recorded every $5{ }^{\circ} \mathrm{C}$ from 25 to $60^{\circ} \mathrm{C}$ (heating rate $1{ }^{\circ} \mathrm{C} / \mathrm{min}$ ), every 1 ${ }^{\circ} \mathrm{C}$ from 60 to $75{ }^{\circ} \mathrm{C}\left(0.2{ }^{\circ} \mathrm{C} / \mathrm{min}\right)$, every $2{ }^{\circ} \mathrm{C}$ from 75 to $90{ }^{\circ} \mathrm{C}(0.5$ $\left.{ }^{\circ} \mathrm{C} / \mathrm{min}\right)$ and every $5{ }^{\circ} \mathrm{C}$ from $90{ }^{\circ} \mathrm{C}$ to $100{ }^{\circ} \mathrm{C}\left(1{ }^{\circ} \mathrm{C} / \mathrm{min}\right)$. The intensities of the spectra were first roughly calibrated with bis(trimethylsilyl)acetylene as an internal reference and it showed that the overall intensity increases and reach a plateau at $60{ }^{\circ} \mathrm{C}$. The overall intensity of the signals of $2 \mathrm{NH}$ and 3 Aromatics was set at 5 and the same normalization factor was applied to the curves below $60^{\circ} \mathrm{C}$.

\section{RESULTS AND DISCUSSION}

The structure of the organogelator studied in this paper, BHPB-10, is shown Scheme 1. BHPB-10 forms gels in alkanes and aromatic solvents. We have shown previously that the gels formed at concentrations of a few wt. percent are composed of nanotubes with lengths of several micrometers and diameters of $27 \mathrm{~nm}$ with a very low dispersity $(<5 \%)$. ${ }^{17,18}$ Here we have studied this gelator in trans-decalin to prevent evaporation during the experiments, especially the rheological measurements.

Scheme1. Chemical structure of BHPB10 with numbering of the aromatic protons for NMR studies.

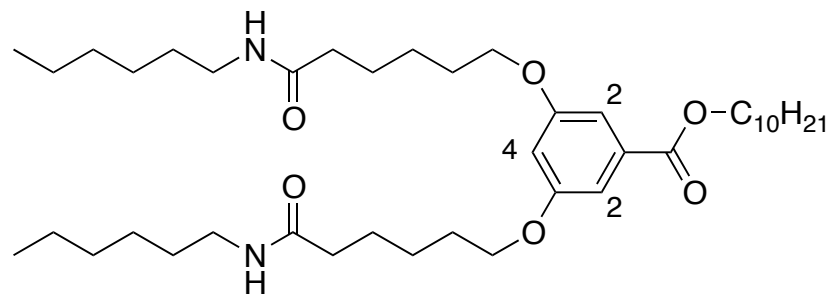

Establishment of the phase diagram. We have first built the phase diagram of BHPB10/trans-decalin mixtures upon cooling. Samples at different concentrations were heated at $100{ }^{\circ} \mathrm{C}$ and cooled at a rate of $-0.25^{\circ} \mathrm{C}$. The sol-to-organogel 
transition has been studied by different methods: mechanical measurements, DSC, optical microscopy and light intensity transmission. As an example, Fig. 1 represents all the quantities measured by the different techniques on samples at $c=2$ wt $\%$. The left axis reports the variations of the elastic modulus $G^{\prime}$ and loss modulus $G^{\prime \prime}$ with temperature. At high temperatures, the response of the sample is of liquid type with $\mathrm{G}^{\prime \prime}>>$ $G^{\prime}$. As the temperature decreases, $G^{\prime}$ and $G^{\prime \prime}$ values do not show any significant change up to $\sim 54{ }^{\circ} \mathrm{C}$. At this temperature, $G^{\prime}$ and $G^{\prime \prime}$ increase abruptly and $G^{\prime}$ becomes greater than $G^{\prime \prime}$. Therefore the response of the sample switches from liquid-like $\left(G^{\prime \prime}>G^{\prime}\right)$ to solid-like $\left(G^{\prime}>G^{\prime \prime}\right)$ in a small temperature range. The temperature for which $G^{\prime}=G^{\prime \prime}$ is noted $T_{\text {gel }}$ and is considered as the temperature of the liquid-solid transition. This change in behavior from liquid to solid was observed and $T_{g e l}$ was measured for concentrations ranging from $0.05 \%$ to $15 \%$.

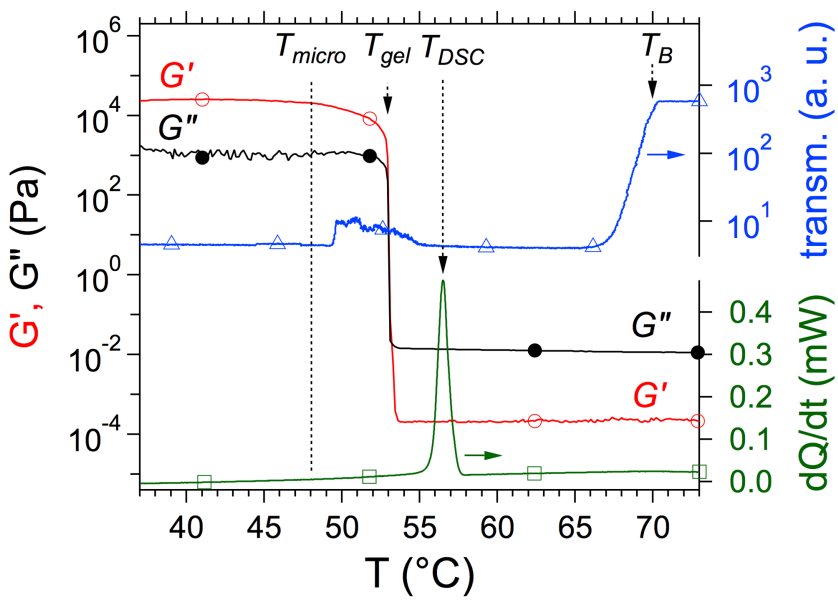

Figure 1. Temperature dependence of the quantities determined by rheology, DSC and light transmission on a BHPB10/transdecalin sample ( $c=2$ wt. $\%$; cooling rate: $\left.-0.25^{\circ} \mathrm{C} / \mathrm{min}\right)$. $\bigcirc: G^{\prime}$; -: $G^{\prime \prime}$ (shear measurements performed at $1 \mathrm{~Hz}$ ). The gelation temperature $T_{g e l}$ is defined as the temperature for which $G^{\prime}=G^{\prime \prime}$. $\triangle$ : intensity of light transmitted through the sample. The strong decrease at the temperature called $T_{B}$ corresponds to a liquidliquid phase separation. For $c=2 \%, T_{B}=70.5^{\circ} \mathrm{C}$. $\square$ : heat flow measured by DSC. $T_{D S C}$ is defined as the maximum of the exotherm. $T_{\text {micro }}$ is the temperature where the formation of the fibers becomes visible by optical microscopy.

A striking feature of the $G^{\prime}$ and in $G^{\prime \prime}$ curves in Fig. 1 is the abrupt increase at $T_{\text {gel }}$. Above $T_{\text {gel }}, G^{\prime \prime}$ varies slightly and regularly. The viscosity derived from $G^{\prime \prime}$ follows Arrhenius' law, which means that before $T_{\text {gel }}$ the solution is a fluid without aggregates. Therefore the gelation does not proceed through an increase of the size or proportion of aggregates for which a progressive increase of $G^{\prime}$ and $G^{\prime \prime}$ is expected. The steep increase in $G^{\prime}$ and $G^{\prime \prime}$ suggests a nucleation-growth mechanism. This statement is valid for concentrations above $0.6 \%$. Below this concentration, gradual increase in $G^{\prime}$ and $G^{\prime \prime}$ may occur, but it is too close to the detection limit to draw any firm conclusion.

The samples were studied also by DSC at the same cooling rate of $0.25{ }^{\circ} \mathrm{C} / \mathrm{min}$. The thermograms show a sharp exothermic peak, characteristic of a first order transition, for concentrations as low as $0.1 \mathrm{wt}$ \% (Fig. 2). The temperature corresponding to the maximum of the peak is noted $T_{D S C}$ and is

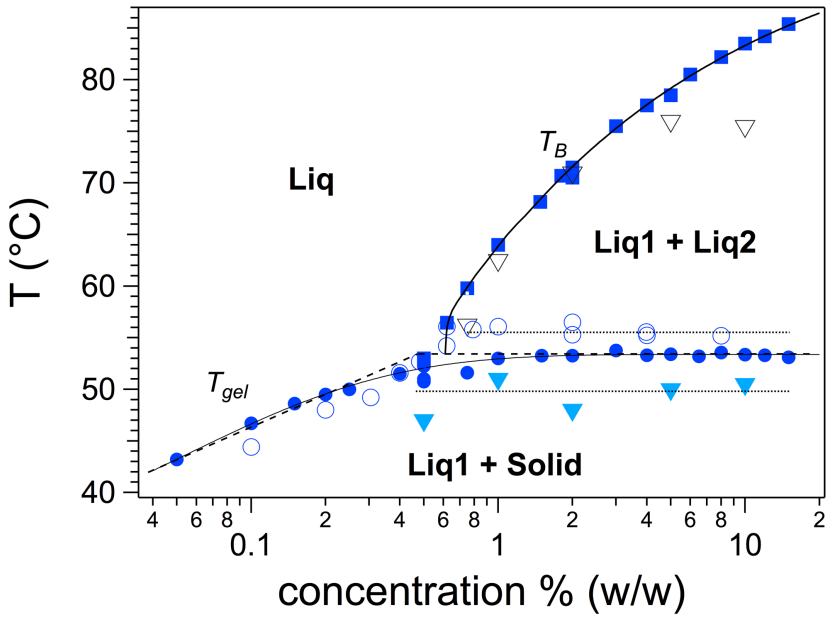

Figure 2. Temperature-concentration phase diagram for BHPB10$10 /$ trans-decalin for a cooling rate of $-0.25^{\circ} \mathrm{C} / \mathrm{min}$. $: T_{\text {gel }}$. $\bigcirc$ : $T_{D S C} . \nabla: T_{\text {micro }}$ (see text and legend of Fig. 1 for the definition of the temperatures). $\square: T_{B}$, temperature of the liquid-liquid phase separation, measured by light intensity. $\nabla: T_{B}$ measured by microscopy. Above $c_{L} \sim 0.6 \%, T_{g e l}$ is independent from c, which is a consequence of the miscibility gap. The lines are just guides for eyes.

measured for concentrations up to $8 \% . T_{D S C}$ and $T_{\text {gel }}$ values are plotted together in Fig. 2. Below $c_{L} \sim 0.6 \%, T_{\text {gel }}$ and $T_{D S C}$ progressively increase with c. For concentrations above $c_{L}, T_{g e l}$ and $T_{D S C}$ remain at constant values of $53.1 \pm 0.3{ }^{\circ} \mathrm{C}$ and $55.3 \pm$ $0.4{ }^{\circ} \mathrm{C}$ respectively. The plateau spreads over a decade of con-centrations and cannot be attributed to a lack of precision in the measurements. In summary, both mechanical and thermal experiments clearly show two regimes: an increase at low concentrations and a plateau above a threshold concentration.

In order to explain the existence of the plateau, samples at different concentrations above $c_{L}$ were observed by microscopy while they were cooled at the same rate as for rheological and thermal experiments. The figure 3 presents the micrographs obtained for two concentrations in the regime of the plateau: 2 and $10 \%$. At high temperature, the sample is homogeneous. At a temperature named $T_{B}$, droplets form and the sample becomes heterogeneous. As shown by X-ray experiments, the system is completely amorphous so both the droplets and the continuous phases are liquid. It is also consistent with the absence of variation of $G^{\prime}$ or $G^{\prime \prime}$ while the biphasic system appears. Below $T_{B}$, the system lies therefore in a miscibility gap where two liquids of different compositions coexist, liquid $1+$ liquid 2 . When the sample is cooled further, at a temperature called $T_{\text {micro }}$ the droplets explode and give birth to long fibers. For $c=2 \% ; T_{\text {micro }}=48{ }^{\circ} \mathrm{C}$. The transition occurs at a front corresponding the fiber ends. When the temperature decreases, the fibers grow and the front moves from areas containing mainly fibers to the liquids. The observed dynamic and morphology are consistent with a nucleation-growth mechanism. Finally, well below $T_{\text {micro }}$, the front has moved past the limits of the observed area, leaving an increased fraction of fibers. $T_{\text {micro }}$ was measured for different concentrations and is also plotted in Fig. 2. For this $c>c_{L}, T_{\text {micro }}$ is constant within uncertainty $\left(48-51^{\circ} \mathrm{C}\right)$, like $T_{g e l}$ and $T_{D S C}$.

The liquid-liquid phase separation was also studied by measuring the light intensity transmitted by samples cooled at $-0.25{ }^{\circ} \mathrm{C} / \mathrm{min}$ (same as microscopy and mechanic). As an 


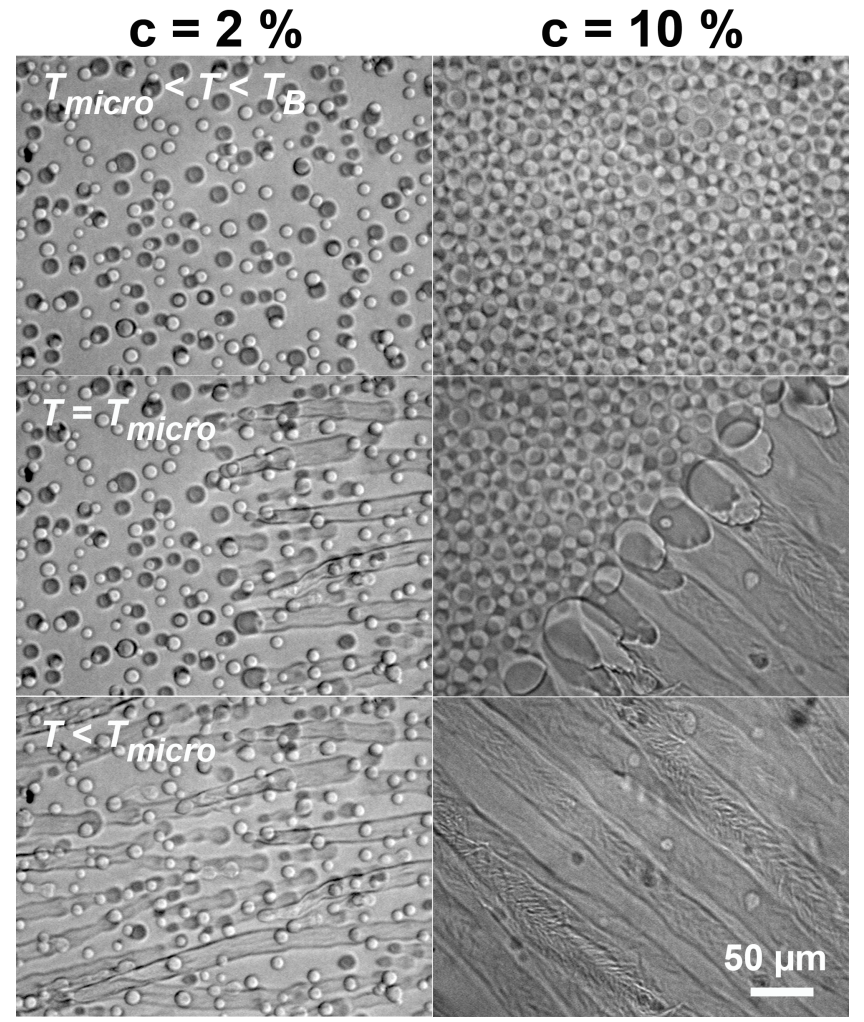

Figure 3. Optical micrographs of BHPB10/trans-decalin (2 and $10 \%)$ at different temperatures. $T_{B}$ is the temperature for which the droplets appear. $T_{\text {micro }}$ is the temperature for which the fibers and the liquid phases coexist.

example the intensity measured for a $2 \%$ sample is represented on Fig.1. The curve shows two changes: the first is a brutal decrease of the intensity at $70.5{ }^{\circ} \mathrm{C}$. It corresponds to a sudden increase in light scattering because the droplets form. The steep decrease yields another value of $T_{B}$, close to the one measured by microscopy $\left(71^{\circ} \mathrm{C}\right)$. The second change is a broad peak with a moderate and fluctuating intensity starting 2 ${ }^{\circ} \mathrm{C}$ above $T_{\text {gel }}$ measured by rheology $\left(G^{\prime}\right.$ and $G^{\prime \prime}$ crossover at $53{ }^{\circ} \mathrm{C}$ ) and ending $4{ }^{\circ} \mathrm{C}$ below. This peak is too wide to define a sharp transition temperature; nevertheless the light intensity experiments clearly distinguish two distinct transitions as for the OM measurements: the liquid-liquid phase separation at high temperature and the formation of the gel at lower temperature.

Assignment of the phase diagram. As shown by the different experiments described above, the phase diagram established on cooling shows three domains (Fig. 2): a homogeneous liquid phase at high temperature (liquid), a heterogeneous liquid phase consisted of a suspension of droplets (liquid $1+$ liquid 2) also called miscibility gap, and the gel (solid + liquid 1). In the gel, the solid phase corresponds to the aggregates containing mostly the gelator and possibly a small ratio of solvent. Below the threshold $c_{L} \sim 0.6 \%$, there is no miscibility gap: when the solution is cooled the only transition is the formation of the gel at $T_{\text {gel }}$ : liquid $\rightarrow$ solid. $T_{\text {gel }}$ increases with $c$, and its aspect is frequently encountered in organogels. Above $c_{L}$, the miscibility gap appears and the sample undergoes two transitions when cooled. The first one, at $T_{B}$ corresponds to the liquid-liquid phase separation (liquid $\rightarrow$ liquid $1+$ liquid 2). $T_{B}$ depends on the concentration and simply corresponds to the binodal curve. Both liquids consist of solutions of BHPB10 in trans-decalin, but the concentration is low liquid 1 and high in liquid 2. For a given temperature, the abscissa of the binodal curve (its ascending branch) equals the concentration of BHPB-10 in liquid 1. The second transition observed upon cooling is the gel formation and occurs at a lower temperature. It can be written liquid $1+$ liquid $2 \rightarrow$ liquid $1+$ solid due to the miscibility gap. It is a monotectic transformation and its temperature noted $T_{g e l}$ here is invariant by virtue of Gibbs' phase rule. ${ }^{19,20}$ All the temperatures measured by different techniques follow this rule, since they are all related to the same transition.

Comparison of the measured temperatures. The transition temperatures measured by DSC and mechanical measurements, $T_{D S C}$ and $T_{\text {gel }}$, are separated by less than $3{ }^{\circ} \mathrm{C} . T_{D S C}$ is slightly greater than $T_{g e l}$ above $c_{L} \sim 0.6 \%$ and slightly smaller than $T_{\text {gel }}$ below. The temperature of the formation of the fibers $T_{\text {micro }}$ is $5{ }^{\circ} \mathrm{C}$ below $T_{\text {gel }}$ and $8-9{ }^{\circ} \mathrm{C}$ below $T_{D S C}$ as shown by (Fig. 1). A strict comparison between the techniques should be done after extrapolation at zero cooling rate. However the gap observed between $T_{\text {micro }}$ and $T_{\text {gel }}$ for the same cooling rate, may be due to the small volumes observed by OM. As shown in Fig. 3, one usually observes the displacement of a single front across the observation field, which is not instantaneous and takes 1 minute. Moreover when the front appears in the view field it has already moved for several minutes from a nucleating point which appeared at a higher temperature. Indeed, the whole capillary volume (less than $1 \mu \mathrm{L}$ ) contains a single (or a few) nucleating points. This low nucleating density explains why $T_{\text {micro }}$ is the lowest measured temperature. In addition, $\mathrm{OM}$ detects the aggregates only when they reach micrometric size, while mechanical and light intensity measurements detect aggregates with smaller sizes, about $100 \mathrm{~nm}$, therefore at a higher temperature than $T_{\text {micro }}$. The size difference also explains why $T_{B}$ values determined by microscopy and by light intensity differ for $c>3 \%$. Light intensity measurements yield higher temperatures than OM, because they are more sensitive. They detect droplets before they grow large enough to be seen by microscopy.

Comparison of diagrams on heating and on cooling. The diagram on Fig. 2 is established only during cooling but the observed transition temperatures and the extent of the domains depend on the cooling rate. Especially does the two liquid phases domain still exist upon heating and what are the boundaries of the corresponding domain? This question has been addressed by establishing the diagram during the heating phase from DSC and optical microscopy experiment as shown by the results reported on the diagram below (Fig. 4).

The optical micrographs obtained during heating show the transformation liquid $1+$ solid $\rightarrow$ liquid $1+$ liquid 2, opposite to that observed on cooling. The temperatures $T_{\text {micro }}$ reported (Fig. 4) are defined as the temperature where both liquids and fibers coexist on micrographs. They are non-variant with $c$ like for the cooling stage, which reflects a monotectic melting. $T_{\text {micro }}$ values obtained on heating (avg. $59.8 \pm 1.7^{\circ} \mathrm{C}$ ) are higher than values obtained on cooling (avg. $49.9 \pm 1.3{ }^{\circ} \mathrm{C}$ ). The thermograms measured by DSC showed endothermic peaks for concentrations as low as $0.01 \%$ and we have reported $T_{D S C}$ as the temperature of the maximum of the peak (Fig. 4).

Like the experiments during cooling, $T_{D S C}$ follows two regimes: below $c_{L}$, it varies with $T$ and above $c_{L}$ it becomes constant (avg. $64.8 \pm 0.5{ }^{\circ} \mathrm{C}$ ). Throughout the diagram, the values obtained by DSC on heating are $10{ }^{\circ} \mathrm{C}$ higher than 


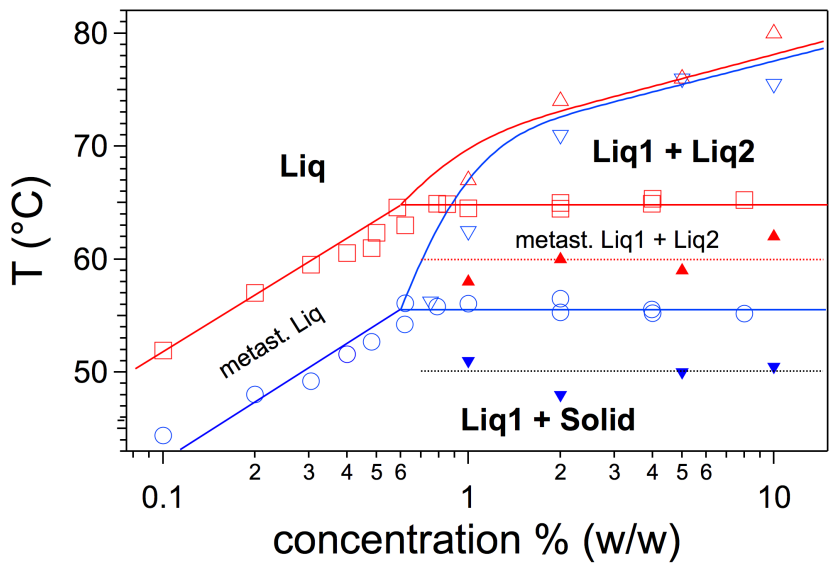

Figure 4. $c$ - $T$ phase diagram for BHPB-10/trans-decalin. Cooling and heating rate: $0.25{ }^{\circ} \mathrm{C} / \mathrm{min}$. $\bigcirc: T_{D S C}$ upon cooling; $\nabla: T_{B}$ measured on cooling by microscopy; $\boldsymbol{\nabla}: T_{\text {micro }}$ (same as in Fig. 2). $\square: T_{D S C}$ measured on heating (maximum of the endotherm). $\triangle$ : $T_{B}$ measured on heating by DSC. $\boldsymbol{\Delta}: T_{\text {micro }}$ measured on heating (temperature of coexistence of fibers and biphasic liquid).

those for the values obtained by OM. The significant discrepancy highlights that the gelation of this compound proceeds via homogeneous nucleation: gelation starts only from a critical nucleus of BHPB-10 molecules unlike other systems where impurities trigger the nucleation and growth. This process is commonly observed in other gels. Within the gap the two liquid phases are observed on cooling, but are metastable. By optical microscopy during heating, we observed the transition from the biphasic liquid to the homogeneous liquid, liquid $1+$ liquid $2 \rightarrow$ liquid. It occurs at temperatures slightly higher than for the reverse transformation, but the gap between the temperature on heating and cooling is less significant the gap between gel formation and gel melting. It is justified, since the Liquid $\rightarrow$ Liquid $1+$ Liquid 2 transition occurs also through a nucleation and growth process but in most cases through heterogeneous nucleation as an impurity will do. In summary, the complete diagram has been mapped out both on cooling and heating. In both cases, we explain the presence of a plateau on an experimental basis, by a monotectic transformation. This approach is different from that of Feng and Cavicchi, ${ }^{21}$ based on solubility parameters theory. They show that for some parameters, the gel melting temperatures curves can flatten out at high $c$. In their study, the whole curve corresponds to a continuous liquidus; in our case the liquidus exists only below $c_{L} \sim 0.6 \%$ and is replaced by a monotectic above.

Study of the molecular interactions in the different phases. These interactions have been investigated by FTIR. Indeed, the characteristic modes of the amides are very sensitive to $\mathrm{H}$-bonds and their shifts represent semi-quantitative markers of the strength of the H-bonds: $:^{22,23}$ the amide A arising from interatomic $\mathrm{NH}$ stretching $\left(v_{\mathrm{NH}}\right)$, the amide I corresponding mainly to $\mathrm{CO}$ stretching coupled to $\mathrm{CN}$ and $\mathrm{NH}$ vibrations $\left(v_{\mathrm{CO}}\right)$ and amide II $\left(v_{\mathrm{CN}}+\delta_{\mathrm{NH}}\right)$. A sample at 2 wt. $\%$ was heated at $100{ }^{\circ} \mathrm{C}$ and cooled to $25^{\circ} \mathrm{C}$ at the same cooling rate than the previous experiments $\left(-0.25{ }^{\circ} \mathrm{C} / \mathrm{min}\right)$ and spectra were recorded at different temperatures (Fig. 5).

We shall first discuss the aspect of the spectra in between 100 and $70{ }^{\circ} \mathrm{C}$, in the monophasic liquid. In the 3200-3500 $\mathrm{cm}^{-1}$ range (Fig. 5 right), the principal contributions are the amide A bands. At $100{ }^{\circ} \mathrm{C}$, they consist in a broad band at 3354 and a narrow band at $3455 \mathrm{~cm}^{-1}$. The band at $3455 \mathrm{~cm}^{-1}$

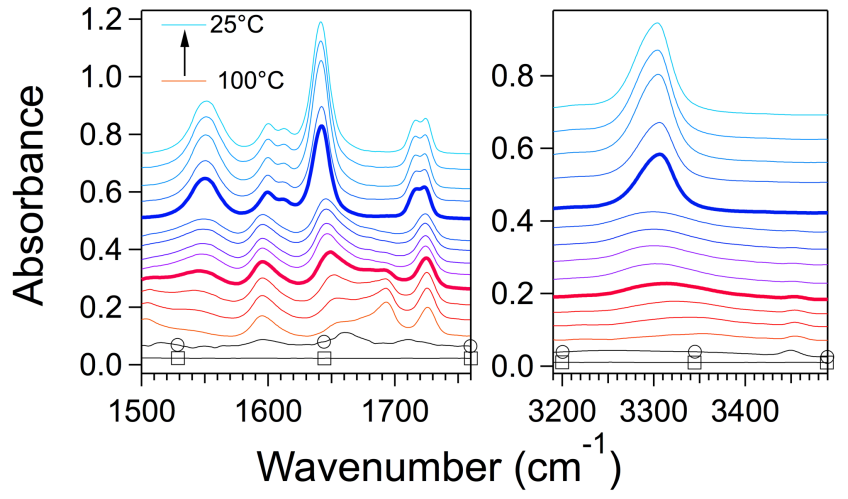

Figure 5. FTIR of BHPB10 in trans-decalin (2 wt. \%) at decreasing temperatures $(100,90,80,70,63,60,58,55,53,47,39,30$, $25^{\circ} \mathrm{C}$ ) Left: region of amide I and II bands. Right: region of the amide A bands. The bold line at $70{ }^{\circ} \mathrm{C}$ is the first spectrum below the biphasic transition and the bold line at $53{ }^{\circ} \mathrm{C}$, the first spectrum below the gel transition. $\mathrm{O}$ : BHPB10 in $\mathrm{CHCl}_{3}$. $\square$ : transdecalin.

corresponds to non-bonded NH groups. Indeed, it is comparable with the only band exhibited in $\mathrm{CHCl}_{3}$ where no aggregation occurs. The broad band centered at $3354 \mathrm{~cm}^{-1}$, absent in $\mathrm{CHCl}_{3}$, proves that part of the amide groups is $\mathrm{H}$-bonded, even at high temperature. It also indicates a broad distribution of $\mathrm{H}$ bonding strengths (fitting in Fig. 6). The position of the maximum of the feature is typical of average weak H-bonds. As for the amide I modes (Fig. 5 Left), at $100{ }^{\circ} \mathrm{C}$, they form a complex massif from 1635 to $1710 \mathrm{~cm}^{-1}$ The most intense peak is localized at $1692 \mathrm{~cm}^{-1}$ and corresponds to the free amides; at lower wavenumbers, between 1676 and $1655 \mathrm{~cm}^{-1}$, the spectrum shows a complex structure assigned to $\mathrm{H}$-bonded amide $\mathrm{I}$, indicating a dispersion of the $\mathrm{H}$-bonding strengths in agreement with the behavior of the amide A. The shifts of $1676 \mathrm{~cm}^{-1}$ and $1655 \mathrm{~cm}^{-1}$ correspond to amide I weakly and more strongly H-bonded respectively. The amide II mode gives rise to two peaks at 1550 and $1500 \mathrm{~cm}^{-1}$, corresponding respectively to bonded and free amides.

When $T$ decreases from $100{ }^{\circ} \mathrm{C}$ to $70{ }^{\circ} \mathrm{C}$, while the liquid remains monophasic, the spectra retain the same features, but

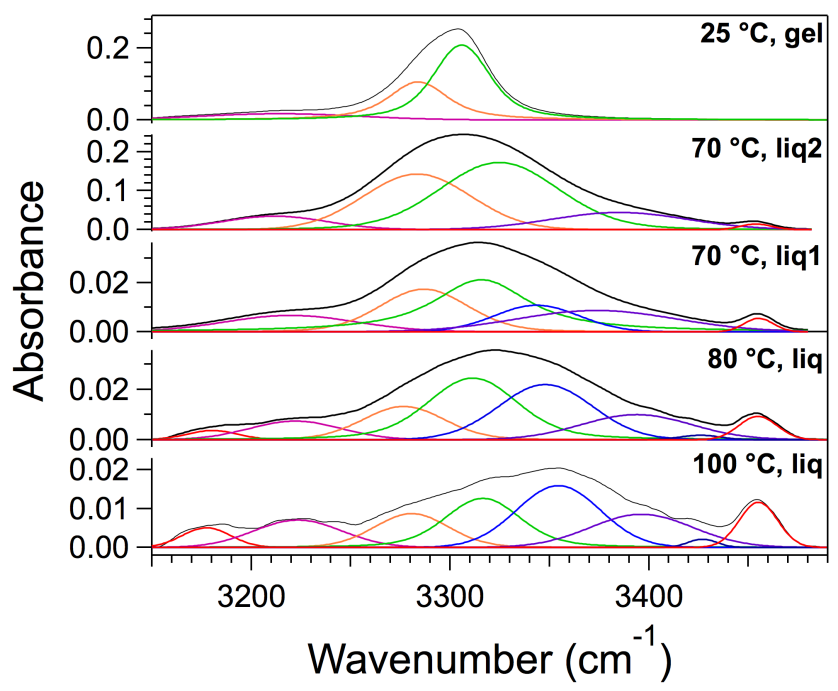

Figure 6. Decomposition of the amide A in different contributions for different temperatures. 
the free amide fingerprints at 3454, 1694 and $1500 \mathrm{~cm}^{-1}$, that predominate at $100{ }^{\circ} \mathrm{C}$, diminish in intensity while their frequency remain constant. Concomitantly, the intensities of the $\mathrm{H}$-bonded amides bands increase $\left(3354,1654\right.$ and $\left.1550 \mathrm{~cm}^{-1}\right)$. As a consequence, the maximum of the $\mathrm{H}$ bonded amide $\mathrm{A}$ bands (from 3354 to $3310 \mathrm{~cm}^{-1}$ ) and amide I bands (from 1654 to $1649 \mathrm{~cm}^{-1}$ ) shifts toward lower frequencies when temperature decreases. The weight transfer of the high frequency modes to the lower frequency ones shows that the H-bonds between amides strengthen when the solution cools.

The transition between the monophasic and biphasic liquids occurs at $72{ }^{\circ} \mathrm{C}$. Just below, at $70{ }^{\circ} \mathrm{C}$, the spectrum shows a decrease of the intensity of the modes of the free amides that eventually vanish at $55^{\circ} \mathrm{C}$. The spectra on Fig. 5 represent the average signal for both liquids, but by IR microscopy we measured separately the spectra of each phase (Fig. 7), inside the droplets (liquid 2) and outside the droplets (liquid 1). The intensity of the spectra is weaker in liquid 1 than in liquid 2 (for clarity the spectra of liquid 1 have been multiplied by 4.3). Liquid 2 (droplets) is rich in solute, while liquid 2 is poorer in solute, which is consistent with the phase diagram. In the amide A band, the relative contributions of the modes associated to the free amide is higher in liquid 1 than in liquid 2 as shown Fig. 7 right and Fig. $6\left(70{ }^{\circ} \mathrm{C}\right.$ liql and liq2). In parallel, the ratios $\mathrm{I}_{1698} / \mathrm{I}_{1653}, \mathrm{I}_{1680} / \mathrm{I}_{1653}$ and $\mathrm{I}_{1500} / \mathrm{I}_{1535}$ are higher in liquid 1 than in liquid 2, which proves a higher proportion of bonded amides in liquid 2. In conclusion, both the gelator concentration and the rate of $\mathrm{H}$-bonded amides are higher in liquid 2 than in liquid 1.

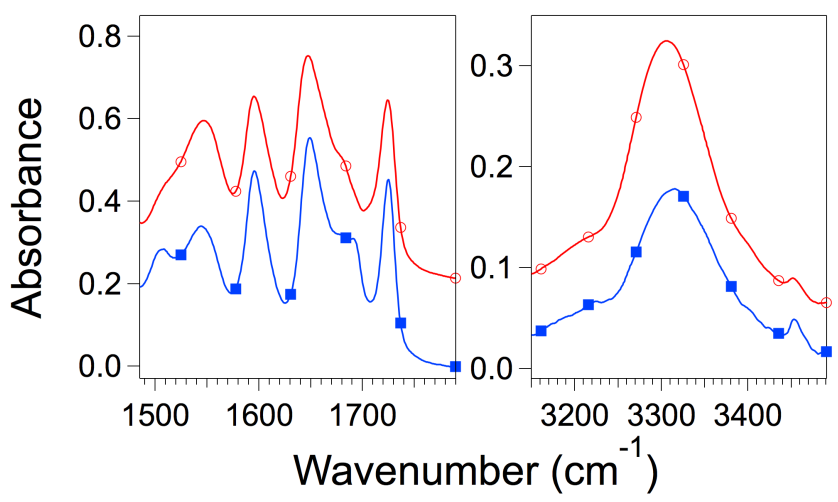

Figure 7. FTIR Spectra in the liq1-liq2 domain $\left(70^{\circ} \mathrm{C}\right)$. $\mathbf{\square}$ : liquid 1 = outside droplets; $\bigcirc$ : liquid 2 = inside droplets. The intensities in liq 1 are multiplied by 4.3 to normalize the intensities of the most intense amide I peaks in liq1 and liq2.

At $53{ }^{\circ} \mathrm{C}$ the systems transits to the gel and the spectrum is characterized by a drastic increase of the intensities of the modes associated to the H-bonded amides: the NH stretching band at $3313 \mathrm{~cm}^{-1}$, the amide I at $1654 \mathrm{~cm}^{-1}$ and the amide II at $1550 \mathrm{~cm}^{-1}$. Moreover, the peaks associated with free amides have disappeared. The present peaks are narrower than in the biphasic liquids and can be resolved in two components only (Fig. 6). These observations are consistent with $\mathrm{H}$-bonds in an ordered system. ${ }^{24,25}$

Because of the many modes observed, it is difficult to determine their molar absorption coefficient and derive the rate of H-bonded species by FTIR. For this reason we have studied the H-bonds in the liquid phases by NMR. A gel of BHPB-10 in trans-decalin $d 18(2 \mathrm{wt} . \%)$ was heated from $25^{\circ} \mathrm{C}$ to $100{ }^{\circ} \mathrm{C}$
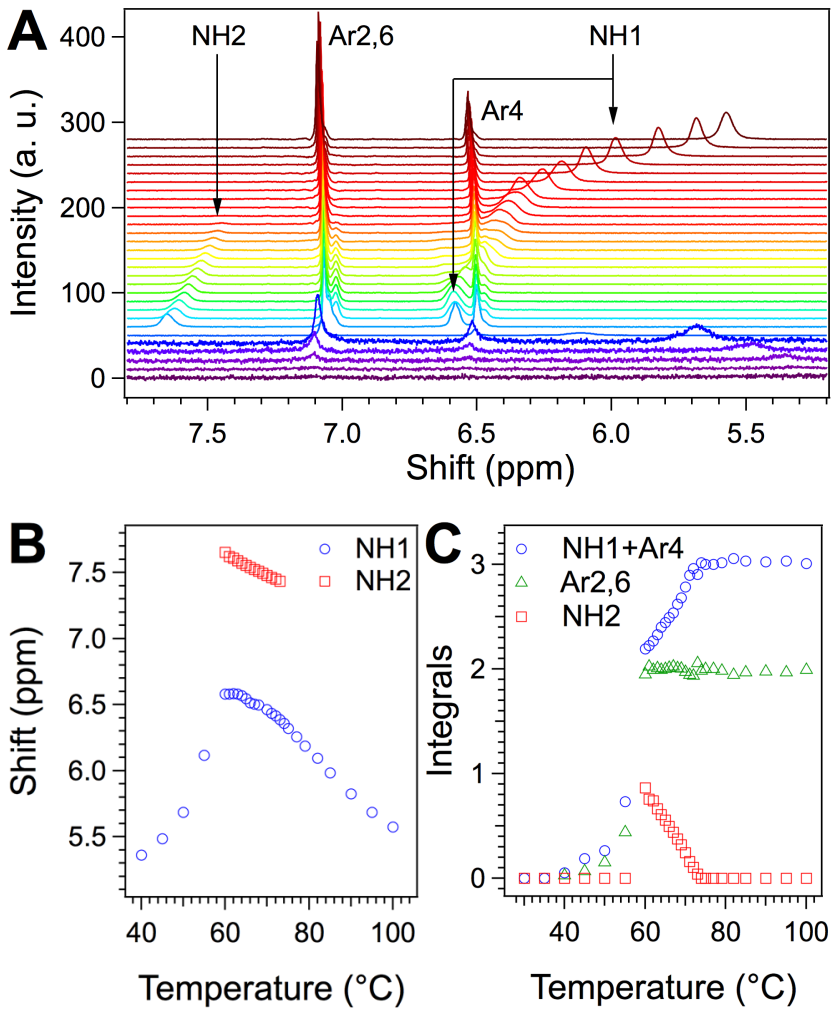

Figure 8. A) NMR spectra of BHPB-10 in trans-decalin $d 18$ (2 wt. \%) at temperatures from 25 to $100{ }^{\circ} \mathrm{C}$. The intensities measured at the first five temperatures $\left(30,35,40,45\right.$ and $\left.50^{\circ} \mathrm{C}\right)$ were multiplied by $10 \mathrm{~B}$ ) Shifts of the NH1 and $\mathrm{NH} 2$ signals vs. temperature. C) Normed integrals of the different signals of the spectra. $\mathrm{NH} 1$ and $\mathrm{Ar} 4$ were integrated together because they overlap in a large range of $T$.

while the NMR spectra were recorded at various temperatures (Fig. 8).

At room temperature the peaks of BHPB-10 are not visible and can be detected only at $40{ }^{\circ} \mathrm{C}$. Their intensities increase with $T$ up to $60^{\circ}$. The molecules immobilized in the gel aggregates are not visible in the spectra, and the visible signal corresponds to the fraction of BHPB-10 that dissociates from the aggregates and solubilizes. This fraction is low at $40{ }^{\circ} \mathrm{C}$ and increases with $T$. The spectrum at $40{ }^{\circ} \mathrm{C}$ shows two peaks at 6.45 and $7.05 \mathrm{ppm}$ that correspond to the aromatic protons, and a broad peak at $5.3 \mathrm{ppm}$ that corresponds to the amide protons $(\mathrm{NH})$. The chemical shift of this peak is the molar fraction average of the shifts of all $\mathrm{NH}$ groups, whether they are H-bonded or not: $\delta=X_{\text {bound }} \delta_{\text {bound }}+\left(1-X_{\text {bound }}\right) \delta_{\text {free }}$, where $\delta_{\text {bound }}$ and $\delta_{\text {free }}$ are the shifts of the bound and free amide respectively, and $X_{\text {bound }}$ is the molar fraction of bounded amides. From this relationship the fraction $X_{\text {bound }}$ can be derived from the values of $\delta_{\text {bound }}$ and $\delta_{\text {free }}$ when they are known. These values have been estimated in the literature ${ }^{26,27}$ by measuring the shifts of solution of model amide with increasing concentrations. The lowest value, reached at lower concentrations, is $\delta_{\text {free }}$ whereas the highest value, reached at high concentrations, is $\delta_{\text {bound }}$. For instance the $\delta_{\text {free }}-\delta_{\text {bound }}$ intervals are $5.2-8.4 \mathrm{ppm}$ for $\mathrm{N}$-methylacetamide in $\mathrm{CD}_{2} \mathrm{Cl}_{2} ; 4.8-8.4$ for the same compound in a $\mathrm{CCl}_{4}-\mathrm{C}_{6} \mathrm{D}_{6}$ mixture, ${ }^{26}$ 4.6-8.2 for $\mathrm{N}$-isopropylacetamide in $\mathrm{C}_{6} \mathrm{D}_{12}{ }^{27}$ We have measured the shifts for $\mathrm{C}_{6} \mathrm{H}_{13} \mathrm{NHCOC}_{5} \mathrm{H}_{11}$ in trans-decalin which models more close- 
ly the amide part of BHPB-10. We found the values $\delta_{\text {free }}=$ $4.89 \pm 0.05 \mathrm{ppm}$ and $\delta_{\text {bound }}=8.29 \pm 0.05 \mathrm{ppm}$.

The chemical shift of BHPB-10 at $40{ }^{\circ} \mathrm{C}$ is low $(5.35 \mathrm{ppm})$ and close to $\delta_{\text {free }}$. It can be deduced that $85 \%$ of the amides groups of the soluble molecules are free and only $15 \%$ of the amides are $\mathrm{H}$-bonded with each others, including through intramolecular bonds. When the temperature increases, the shift increases because the concentration of free BHPB10 increases, which favors intermolecular bonds.

When the gel melts, the sum of the normalized intensities becomes constant (Fig. 8C), which proves that all the molecules are in solution. Between 60 and $73{ }^{\circ} \mathrm{C}$, the $\mathrm{NH}$ signal is split in two peaks. This $T$ interval corresponds to the domain of the two liquid phases. The first peak at higher field, called NH1, shifts from 6.58 to $6.38 \mathrm{ppm}$ (Fig 8B), and its normalized intensity increases from 1.2 to $2 \mathrm{H}$ (Fig. 8C). The second peak at lower field, called NH2, shifts from $7.65 \mathrm{ppm}$ at $60{ }^{\circ} \mathrm{C}$ to $7.44 \mathrm{ppm}$ at $73{ }^{\circ} \mathrm{C}$, while its normalized intensity decreases from 0.85 to $0 \mathrm{H}$. In the same temperature domain, the signals of most of the peaks are also split, although with smaller gap. This systematic splitting proves the presence of two populations of molecules with slow exchange between both. Each $\mathrm{NH}$ signal represents the amide protons in each liquid phase. $\mathrm{NH} 1$ signal corresponds to the protons of the amides in liquid 1 (outside the droplets) since its intensity increases parallel to the liquid 1 fraction with $T$. In a symmetrical way, NH2 corresponds to the amide protons in liquid 2. The NH2 signal lies at higher shifts than $\mathrm{NH} 1$ : the fraction of $\mathrm{H}$-bonded amides is higher inside the droplets than outside. At $60^{\circ} \mathrm{C}$, the shift $\mathrm{NH} 2$ (7.65) represents a fraction $X_{\text {bound }} \sim 80 \%$, whereas the shift of NH1 is $6.51 \mathrm{ppm}$ which represents a fraction $X_{\text {bound }} \sim 50 \%$. The FTIR spectra have shown that the spectra in the droplets are almost invariant, which suggest that the gelator concentration in liquid 2 does not vary significantly. In the $T$ range where this phase exists, the chemical shift of the $\mathrm{NH} 2$ peak varies at a rate of $-0.015 \mathrm{ppm} /{ }^{\circ} \mathrm{C}$, which shows that there is a dynamic exchange between free and bounded amides, and especially that $\mathrm{H}$-bonds are probably intermolecular inside the droplets. $^{26}$

According to NMR experiments, in the liquid phase in equilibrium with the solid, the gelator concentration and the $\mathrm{H}$ bond rate increase simultaneously with $T$. The bonding rate in this phase does not exceed $\sim 50 \%$; once this rate is reached, the second liquid phase forms and contains amides with a higher H-bond rate. For single amide molecules, it has been shown that a strong cooperative effect exists: when amide associates, $\mathrm{n}$-mers form $\mathrm{n}$ more easily than the dimers. ${ }^{27}$ This effect has been shown also for rigid diamides forming only linear aggregates. ${ }^{28}$ BHPB10 is a flexible diamide and can connect and with 4 neighbors and thus form branches. As expected, above a critical bonding rate, it may form networks at the origin of the phase separation.

\section{CONCLUSION}

We have established the full phase diagram of a gelator both on heating and cooling, at controlled heating and cooling rates, and over two decades of concentrations. Above a threshold concentration, both the gel formation and gel melting temperatures become invariant with temperature. We have shown by optical microscopy and light intensity measurements that this plateau is due to a miscibility gap. This behavior may be more general and explain why the phase diagrams of some gelators also exhibit plateaus. When the gel forms at concentrations where the liquid-liquid phase separation takes place, the gel forms abruptly at the monotectic temperature, no aggregates are formed before. The miscibility gap corresponds to the formation of densely and unordered $\mathrm{H}$-bonded aggregates of gelators that become insoluble above a critical size.

Since the efficiency of a gelator is estimated by very low gel concentrations, phase diagrams are usually studied only at low $c$ regions. But this paper shows that the study of gelators at high concentration can give more insight into the phase diagram and thus understand the mechanisms of formation of gels.

\section{AUTHOR INFORMATION}

\section{Corresponding Authors}

guenet@ics-cnrs.unistra.fr, mesini@ics-cnrs.unistra.fr

\section{Notes}

The authors declare no competing financial interest.

\section{ACKNOWLEDGMENT}

This work was funded by the French Research National Agency (ANR, project Matisse, grant 11-BS08-001). E. C is the recipient of a fellowship of the French department for high education and research (MESR, ED 182, 2014-045). We thank Baptiste Blanchard, Clément Beaufils and Adrien Cossec for their help in FTIR measurements, Cathy Saettel and Gilles Watton for their support in micro DSC and Y. Guilbert for his support in VTNMR.

\section{REFERENCES}

(1) Weiss, R. G.; Terech, P. Molecular Gels. Materials with Self-Assembled Fibrillar Network; Springer: Dordrecht, The Netherlands, 2006

(2) Low Molecular Mass Gelators - Design, Self-Assembly, Function; Fages, F., Ed.; Topics in Current Chemistry; Springer Berlin Heidelberg: Berlin, Heidelberg, 2005; Vol. 256.

(3) Hirst, A. R.; Escuder, B.; Miravet, J. F.; Smith, D. K. HighTech Applications of Self-Assembling Supramolecular Nanostructured Gel-Phase Materials: From Regenerative Medicine to Electronic Devices. Angew. Chem., Int. Ed. 2008, 47, 8002-8018.

(4) Du, X.; Zhou, J.; Shi, J.; Xu, B. Supramolecular Hydrogelators and Hydrogels: From Soft Matter to Molecular Biomaterials. Chem. Rev. 2015, 115, 13165-13307.

(5) Beginn, U.; Zipp, G.; Mourran, A.; Walther, P.; Moller, M. Membranes Containing Oriented Supramolecular Transport Channels. Adv. Mater. 2000, 12, 513-516.

(6) Hikmet, R. A. M. Gels of Liquid Crystals and IonConducting Fluids. In Molecular Gels; Weiss, R. G., Terech, P., Eds.; Springer Netherlands, 2006; pp 773-792.

(7) Babu, S. S.; Prasanthkumar, S.; Ajayaghosh, A. SelfAssembled Gelators for Organic Electronics. Angew. Chem., Int. Ed. 2012, 51, 1766-1776.

(8) Fages, F. Electron Conducting and Magneto-Sensitive Gels. In Molecular Gels; Weiss, R. G., Terech, P., Eds.; Springer Netherlands, 2006; pp 793-815.

(9) Weiss, R. G. The Past, Present, and Future of Molecular Gels. What Is the Status of the Field, and Where Is It Going? J. Am. Chem. Soc. 2014, 136, 7519-7530.

(10) Lescanne, M.; Colin, A.; Mondain-Monval, O.; Fages, F.; Pozzo, J. L. Structural Aspects of the Gelation Process Observed with Low Molecular Mass Organogelators. Langmuir 2003, 19, 2013-2020. 
(11) Huang, X.; Terech, P.; Raghavan, S. R.; Weiss, R. G. Kinetics of $5 \alpha$-Cholestan-3 $\beta$-yl N-(2-Naphthyl)carbamate/nAlkane Organogel Formation and Its Influence on the Fibrillar Networks. J. Am. Chem. Soc. 2005, 127, 4336-4344.

(12) Huang, X.; Raghavan, S. R.; Terech, P.; Weiss, R. G. Distinct Kinetic Pathways Generate Organogel Networks with Contrasting Fractality and Thixotropic Properties. J. Am. Chem. Soc. 2006, 128, 15341-15352.

(13) van Esch, J. H.; Schoonbeek, F.; de Loos, M.; Kooijman, H.; Spek, A. L.; Kellogg, R. M.; Feringa, B. L. Cyclic Bis-Urea Compounds as Gelators for Organic Solvents. Chem. Eur. J. 1999, 5, 937-950.

(14) McWatt, M.; Boons, G.-J. Parallel Combinatorial Synthesis of Glycodendrimers and Their Hydrogelation Properties. Eur. J. Org. Chem. 2001, 2001, 2535-2545.

(15) Hirst, A. R.; Smith, D. K.; Feiters, M. C.; Geurts, H. P. M.; Wright, A. C. Two-Component Dendritic Gels: Easily Tunable Materials. J. Am. Chem. Soc. 2003, 125, 9010-9011.

(16) Hirst, A. R.; Coates, I. A.; Boucheteau, T. R.; Miravet, J. F.; Escuder, B.; Castelletto, V.; Hamley, I. W.; Smith, D. K. Low-Molecular-Weight Gelators: Elucidating the Principles of Gelation Based on Gelator Solubility and a Cooperative Self-Assembly Model. J. Am. Chem. Soc. 2008, 130, 9113 9121.

(17) Diaz, N.; Simon, F. X.; Schmutz, M.; Rawiso, M.; Decher, G.; Jestin, J.; Mésini, P. J. Self-Assembled Diamide Nanotubes in Organic Solvents. Angew. Chem., Int. Ed. 2005, 44, 3260-3264.

(18) Simon, F.-X.; Nguyen, T. T. T.; Díaz, N.; Schmutz, M.; Demé, B.; Jestin, J.; Combet, J.; Mésini, P. J. SelfAssembling Properties of a Series of Homologous EsterDiamides - from Ribbons to Nanotubes. Soft Matter 2013, 9 , 8483-8493.

(19) Guenet, J.-M. Contributions of Phase Diagrams to the Understanding of Organized Polymer-Solvent Systems. Thermochim. Acta 1996, 284, 67-83.

(20) He, X.; Herz, J.; Guenet, J. M. Physical Gelation of a Multiblock Copolymer. Macromolecules 1987, 20, 2003-2009.

(21) Feng, L.; Cavicchi, K. A. Investigation of the Relationships between the Thermodynamic Phase Behavior and Gelation
Behavior of a Series of Tripodal Trisamide Compounds. Soft Matter 2012, 8, 6483-6492.

(22) Bantignies, J.-L.; Vellutini, L.; Sauvajol, J.-L.; Maurin, D.; Wong Chi Man, M.; Dieudonné, P.; Moreau, J. J. E. Hydrogen Bonding in Self Organized Lamellar Hybrid Silica. $J$. Non-Cryst. Solids 2004, 345-346, 605-609.

(23) Careri, G.; Buontempo, U.; Galluzzi, F.; Scott, A. C.; Gratton, E.; Shyamsunder, E. Spectroscopic Evidence for Davydov-like Solitons in Acetanilide. Phys. Rev. B 1984, 30 , 4689-4702.

(24) Creff, G.; Pichon, B. P.; Blanc, C.; Maurin, D.; Sauvajol, J.L.; Carcel, C.; Moreau, J. J. E.; Roy, P.; Bartlett, J. R.; Wong Chi Man, M.; Bantignies, J.-L. Self-Assembly of Bridged Silsesquioxanes: Modulating Structural Evolution via Cooperative Covalent and Noncovalent Interactions. Langmuir 2013, 29, 5581-5588.

(25) Dieudonné, P.; Man, M. W. C.; Pichon, B. P.; Vellutini, L.; Bantignies, J.-L.; Blanc, C.; Creff, G.; Finet, S.; Sauvajol, J.L.; Bied, C.; et al. In Situ X-Ray Measurements to Probe a New Solid-State Polycondensation Mechanism for the Design of Supramolecular Organo-Bridged Silsesquioxanes. Small 2009, 5, 503-510.

(26) Gellman, S. H.; Dado, G. P.; Liang, G.-B.; Adams, B. R. Conformation-Directing Effects of a Single Intramolecular Hydrogen Bond: Variable -Temperature NMR and IR Studies on a Homologous Series. J. Am. Chem. Soc 1991, 113 , $1164-1173$

(27) LaPlanche, L. A.; Thompson, H. B.; Rogers, M. T. Chain Association Equilibria. A Nuclear Magnetic Resonance Study of the Hydrogen Bonding of N-Monosubstituted Amides1a. J. Phys. Chem. 1965, 69, 1482-1488.

(28) De Greef, T. F. A.; Smulders, M. M. J.; Wolffs, M.; Schenning, A. P. H. J.; Sijbesma, R. P.; Meijer, E. W. Supramolecular Polymerization. Chem. Rev. 2009, 109, 5687-5754.

(29) Hirst, A. R.; Escuder, B.; Miravet, J. F.; Smith, D. K. HighTech Applications of Self-Assembling Supramolecular Nanostructured Gel-Phase Materials: From Regenerative Medicine to Electronic Devices. Angew. Chem., Int. Ed. 2008, 47, 8002-8018. 